\section{Limb ischemia after coil migration used for a hypogastric aneurysm embolization}

\section{Miquel Gil Olaria ${ }^{1 *}$, Natalia Hernandez Wiesendanger ${ }^{2}$, Clàudia Riera Hernández ${ }^{1}$, Carlos Esteban Gracia ${ }^{1}$ and Secundino Llagostera Pujol ${ }^{1}$}

${ }^{1}$ Vascular Surgery Section, Surgery Department, Hospital Germans Trias i Pujol, Badalona, Spain ${ }^{2}$ Vascular Surgery Section, Surgery Department, Hospital Virgen de la Luz, Cuenca, Spain

\section{Summary}

Hypogastric artery aneurysms are an uncommon entity. When the diameter achieves $>30-35$ $\mathrm{mm}$, they should be treated. Endovascular repair may be considered as first line therapy. One therapeutic option for internal iliac artery aneurysm exclusion is its embolization with or without covering the ostium with a covered stent. They may be some complications when it is not, as a distal coil migration that may produce ischemic symptoms.

We are presenting a 73-years-old male admitted to hospital with an acute right lower limb ischemia caused by a coil migration. He recently underwent a right hypogastric artery aneurysm endovascular treatment by coil embolization without covering the hypogastric ostium with a covered stent. The patient underwent an emergency surgery to remove the coil by a transfemoral surgical approach with posterior thrombectomy of the secondary thrombus. Actually, he remains asymptomatic and with right posterior tibial pulse.

Covered stent placement at the common iliac artery and external iliac artery could be the best option to avoid the risk of aneurysm rupture caused by endotension and the risk of distal coil migration.

\section{Introduction}

Hypogastric artery aneurysms are an uncommon entity. The estimated incidence in general population is about $0,03 \%$ [1]. It is more frequent in association with abdominal aortic aneurysm, where the incidence rises up to $0,4 \%$ - 5\% or with common iliac artery aneurysm, where the incidence grows up to $29 \%$ [2]. The incidence increases with the age and the male gender [3].

We define a hypogastric artery aneurysm those larger than $20 \mathrm{~mm}$. They are generally asymptomatic. When they give clinical signs and symptoms, those are consequence of growth and the compression of pelvic structures (genitourinary obstruction, venous or nervous compression...) or the rupture of the aneurysm [4,5]. In case of IIAA ruptured, the mortality rises up to $30 \%$ [5]. There is discordance between the diameter of the aneurysm and the rupture risk. Although there is no consensus about which is the recommended treating diameter in asymptomatic IIAA, it has been suggested to treat those that exceed $30-35 \mathrm{~mm}$ size [6].
More Information

*Address for Correspondence: Miquel Gil Olaria, Carretera de Canyet, s/n; 08916 Badalona; Barcelona; Spain, Email:m.gilolaria@gmail.com

Submitted: December 15, 2020

Approved: February 09, 2021

Published: February 10, 2021

How to cite this article: Olaria MG,

Wiesendanger NH, Hernández CR, Gracia CE, Pujol SL. Limb ischemia after coil migration used for a hypogastric aneurysm embolization. Arch Case Rep. 2021; 5: 004-006.

DOI: 10.29328/journal.acr.1001045

Copyright: @ 2021 Olaria MG, et al. This is an open access article distributed under the Creative Commons Attribution License, which permits unrestricted use, distribution, and reproduction in any medium, provided the original work is properly cited.

Keywords: Iliac Aneurysm; Embolization, Therapeutic; Lower extremity; Ichemia

Check for updates

OPEN ACCESS
Actually, due to the low incidence and the absence of large case series, it cannot be established and standardized the treatment for IIAA. It is difficult to get larger series to achieve conclusions due to the low incidence of IIAA.

The classic treatment was the exclusion of the aneurysm with the proximal ligation of the hypogastric artery or the aneurismoraphy. However, in the recent years, endovascular treatment has replaced the open surgery and it must be considered as first therapeutic option [7].

We report a right lower limb ischemia caused by a coil migration in a patient who recently underwent a right hypogastric artery aneurysm endovascular treatment.

\section{Case report}

A 73-years-old male was admitted to the hospital with an asymptomatic right hypogastric aneurysm (IIAA), which had a maximum diameter of $30 \mathrm{~mm}$. The length of proximal neck was $7 \mathrm{~mm}$ and it did not have distal neck. He had also hypertension, 
dyslipidemia, chronic heart failure due to a previous ischemic heart attack complication and an asymptomatic abdominal aorta aneurysm (AAA) which had a maximum diameter of $33 \mathrm{~mm}$, treated endovascularly.

The aneurysm sac was embolized with three coil sized 20 $\mathrm{mm} \times 10 \mathrm{~cm}$ and two coils of $8 \mathrm{~mm} \times 10 \mathrm{~cm}$. There were no perioperative complications and the patient was discharged two days after de procedure.

Three weeks after the surgery, the patient came into the emergency service. He refereed short distance intermittent claudication worsening until rest pain apparition in the last twelve hours.

Physical examination showed pulses absent at the right lower limb with a pale and cold foot. Sensitivity and mobility were preserved.

A duplex-US was performed showing an EIA (External iliac artery) occlusion with a hyperecogenic and linear image with posterior reinforcement at the right distal external iliac and proximal common femoral arteries with distal recanalization at the CFA (Common femoral artery) which showed a monophasic waveform.

A contrast-enhanced CT-scan was done to complete the study. It confirmed the EIA occlusion with distal recanalization at the CFA and showed a coil migration from the right hypogastric artery to the EIA (Figure 1).

The patient underwent an emergency surgery to remove the coil by a transfemoral surgical approach with posterior thrombectomy of the secondary thrombus. At the end of the procedure, the patient had palpable right posterior tibial pulse (Figure 2).

The patient was discharged 48 hours after the surgical intervention without presenting any complication. The patient is currently being monitored as an outpatient and 6 weeks later remains asymptomatic and with right posterior tibial pulse.

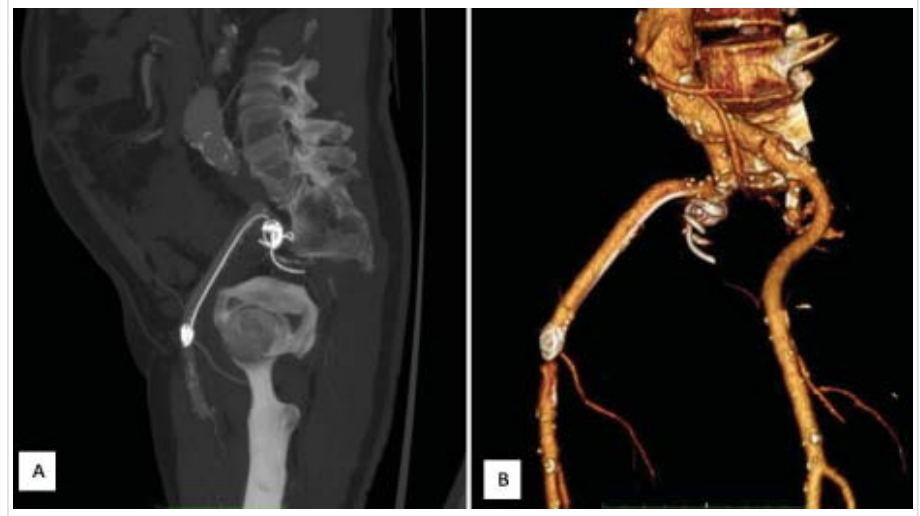

Figure 1: Urgent contrast-enhanced CT-scan sagittal view (a) and 3D-reconstruction (b) showing the coil migration, the coil extends from the right hypogastric to the common femoral artery along the external iliac artery. It can also be observed the correct hypogastric aneurysm exclusion with no endoleaks after embolization with coils.

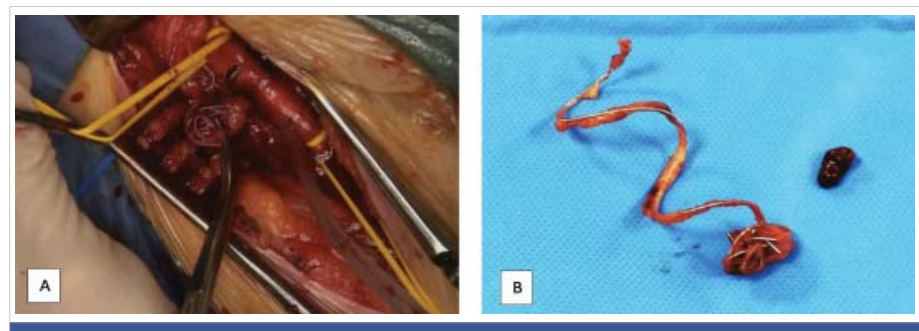

Figure 2: Common femoral artery surgical approach and coil extraction through the transversal arteriotomy (a) and coil shape with some thrombus around it after being removed.

\section{Discussion}

As in the endovascular treatment of the abdominal aortic aneurysm, IIAA anatomy is essential to opt for an endovascular choice $[8,9]$.

Proximal and distal landing zone of hypogastric aneurysm are essential for a proper endovascular device fixation. The endovascular surgical options are the following:

- Aneurysm exclusion with a covered stent: It should be useful when there is a favorable proximal and distal landing zone (at least $14 \mathrm{~mm}$ ) to guarantee the sealing

- Use of an iliac branch device: It is useful when there is a good distal hypogastric sealing zone, but not a proximal one

Preservation of pelvic circulation is the aim of both techniques to avoid pelvic ischemic complications such as buttock claudication, erectile dysfunction, colonic ischemia and/or medullar ischemia.

However, most of IIAA does not have a favorable anatomy for those techniques. Most authors agree the best treatment is the aneurysm sac embolization with coils to improve the thrombosis of the aneurysm [8,10]. Coils must be placed proximally to preserve the most collateral pelvic flow possible and prevent the pelvic ischemia risk $[7,8]$.

There are some discrepancies in the seal of the hypogastric ostium with a covered stent from common iliac artery to external iliac artery. Most authors agree on the stent placement to avoid distal embolization and to reduce the inner pressure of the sac and it possible rupture [10]. It should be a selfexpansible stent because they are more adaptable to the iliac tortuosity and keep radial force.

We did not find any clinical case previously published of accidentally distal coil migration to the iliofemoral segment after IIAA sac embolization.

In our case, it was decided not to implant a covered stent after embolization. As a complication, one coil was stucked into external iliac artery. Once diagnosticated the complication, different approach attitudes were considered: 
- Endovascular coil remove by using a snare through a contralateral access, but it was refused because of the distal embolization risk

- Coil endovascular exclusion against the wall by covered sent placement at the common femoral artery (CFA), but we refused this option as being a flexion zone and for future surgical options preservation

- Transfemoral surgical approach with posterior thrombectomy controlling distal flow to avoid distal embolization

Finally, the transfermoral surgiral approach was performed because it was the fastest avaliable and the most secure option to solve the acute ischemia avoiding future complications.

\section{Conclusion}

Aneurysms of internal iliac artery are a rare entity. The widely accepted treatment in the IIAA when there is no proximal o distal favorable sealing zone is the aneurysm sac embolization. Covered stent placement at the common iliac artery and external iliac artery could be the best option to avoid the risk of aneurysm rupture caused by endotension and the risk of distal coil migration.

\section{Authors' contributions}

GilOlaria,Miquel:Conceptualization, Methodology,WritingOriginal draft.

Hernandez Wiesendanger, Natalia: Methodology, WritingOriginal draft.

Riera Hernández, Claudia: Methodology, Writing-Review and Editing, Project Administration.

Esteban Gracia, Carlos: Methodology, Writing-Review and Editing.

Llagostera Pujol, Secundino: Conceptualization, Supervision, Project administration.
Congresses: This paper was presented as poster at the $I V$ international congress Endovascular surgery chapter Congress that was held in Oviedo on November $13^{\text {th }}-15^{\text {th }}$.

\section{References}

1. Brunkwall J, Hauksson H, Bengtsson $H$, Bergqvist D, Takolander R, et al Solitary aneurysms of the iliac arterial system: An estimate of their frequency of occurrence. J Vasc Surg. 1989; 10: 381-384.

PubMed: https://pubmed.ncbi.nlm.nih.gov/2795762/

2. Rana MA, Kalra M, Oderich GS, de Grandis E, Gloviczki P, et al. Outcomes of open and endovascular repair for ruptured and nonruptured internal iliac artery aneurysms. J Vasc Surg. 2014; 59: 634-644. PubMed: https://pubmed.ncbi.nlm.nih.gov/24571938/

3. Forsdahl SH, Singh K, Solberg S, Jacobsen BK. Risk factors for abdominal aortic aneurysms: a 7-year prospective study: the Troms $\varnothing$ Study, 1994-2001. Circulation. 2009; 119: 2202-2208.

PubMed: https://pubmed.ncbi.nlm.nih.gov/19364978/

4. Wilhelm BJ, Sakharpe A, Ibrahim G, Baccaro LM, Fisher J. The 100Year Evolution of the Isolated Internal lliac Artery Aneurysm. Ann Vasc Surg. 2014; 28: 1070-1077.

PubMed: https://pubmed.ncbi.nIm.nih.gov/24333603/

5. Brin BJ, Busuttil RW. Isolated Hypogastric Artery Aneurysms. Arch Surg. 1982;117: 1329.

PubMed: https://pubmed.ncbi.nlm.nih.gov/6896988/

6. McCready RA, Pairolero PC, Gilmore JC, Kazmier FJ, Cherry KJ, et al. Isolated iliac artery aneurysms. Surgery. 1983; 93: 688-693. PubMed: http://www.ncbi.nlm.nih.gov/pubmed/6845175

7. Wanhainen A, Verzini F, Van Herzeele I, Allaire E, Bown M, et al European Society for Vascular Surgery (ESVS) 2019 Clinical Practice Guidelines on the Management of Abdominal Aorto-iliac Artery Aneurysms. Eur J Vasc Endovasc Surg. 2019; 57: 8-93.

PubMed: https://pubmed.ncbi.nlm.nih.gov/30528142/

8. Ballesteros-Pomar M. Aneurismas de arteria iliaca: Actualización y algoritmos de decisión. Angiologia. 2017; 69: 291-298.

9. Kliewer M, Plimon M, Taher F, Walter C, Hirsch K, et al. Endovascular treatment of hypogastric artery aneurysms. J Vasc Surg. 2019; 70: 1107-1114.

PubMed: https://pubmed.ncbi.nlm.nih.gov/31147136/

10. Malgor RD, Oderich G. Diagnosing and managing internal iliac artery aneurysms. 2015. 